\title{
Editorial January 2019
}

\author{
Paul K. Newton ${ }^{1}$
}

Published online: 19 January 2019

○ Springer Science+Business Media, LLC, part of Springer Nature 2019

There will be a partial 'changing of the guard' at the Journal of Nonlinear Science starting in 2019. Our friend and colleague, K.R. Sreenivasan, who has served as the journal's co-Editor-in-Chief over the past several years, will be stepping down.

When Sreeni and I took over operation of the journal in 2011, our mission was to broaden its scientific coverage, while retaining its reputation for high-quality articles that allowed authors the freedom to fully explain their results without imposing page limitations or charges. We did this, first and foremost, by broadening out the list of communicating editors who are so crucial in vetting all of the submissions and setting the scientific tone for the journal. We also began enlisting a cadre of invited special editors to organize topical focal issues with invited authors. Several of these issues are now in print, the most recent being on 'Small Scales and Singularity Formation in Fluid Dynamics,' one of Sreeni's favorite topics. Sreeni's impeccable reputation in the international community of scholars, scientific taste and temperament, ability to communicate, cajole, humor, and delegate has been invaluable in carrying out our mission. More than any single contribution we could name, his presence and sage advice on every issue has been crucial to the ongoing success and broadening of the journal over the past several years. After the publication of 48 issues and almost 400 articles (40 of them Open Access) in 8 new volumes since 2011, we believe his efforts have left the journal in a healthier state, with more visibility to the wider nonlinear science community of scholars. Our words cannot thank him enough for the hours of service he has donated to this effort, always with good humor and a unique gentlemanly touch.

We welcome Alain Goriely from Oxford and Anthony Bloch from the University of Michigan, who will work with me over the next several years as co-Editors-inChief. Alain's work lies at the interface of nonlinear mechanics, mathematical biology, physics, and applied mathematics, all of which are increasingly important areas of nonlinear science. Tony's work in geometric mechanics, nonlinear control, integrable and non-integrable systems remains crucial to our growing field. Both significantly broaden our scientific coverage and add to our international visibility. Their wide

\footnotetext{
$凶 \quad$ Paul K. Newton

newton@usc.edu

1 Los Angeles, USA
} 
experience in our community, excellent judgment and taste, will help us move the journal forward.

We look forward to publishing your best contributions to the field of nonlinear science over the next several years in this rapidly changing and exciting field!

\section{Paul K. Newton \\ Co-Editor-in-Chief \\ University of Southern California}

Publisher's Note Springer Nature remains neutral with regard to jurisdictional claims in published maps and institutional affiliations. 